\title{
From direct to trunk-and-feeder public transport services in the Urban South: Territorial implications
}

\author{
Pablo Salazar Ferro ${ }^{\text {a }}$ \\ University of Cape Town
}

\author{
Roger Behrens ${ }^{b}$ \\ University of Cape Town
}

\begin{abstract}
In the Global South, many ongoing public transport improvement initiatives are based on a complete restructuring of the existing system. More often than not, plans call for an eventual absorption of incumbent operators into a new "formal" system or for a more radical eradication. These operators are often considered by city authorities to be the cause of inefficient transport systems. When implementing bus-rapid-transit-based plans, public transport improvement initiatives typically propose the transformation of paratransit-based direct services into feeder-trunk-distributor models that introduce new "formal" and "modern" modes. The move from direct services to feeder-trunk-distributor services can, however, have significant implications for travel patterns within the urban territory. Formal feeder-trunk-distributor public transport systems are more rigid than the paratransit-based model they are meant to replace. Some areas of cities in the Global South, generally located in peripheral zones, are growing and changing rapidly, and as such they ideally require a public transport system that is flexible and demand-responsive to fulfill their residents' basic access needs. With the introduction of formal-only trunk-and-feeder schemes, some of these benefits of paratransit services are lost. Without disregarding the need for paratransit upgrade in terms of operations and business practices, it is argued that complementarity between formal and paratransit services is possible within a feeder-trunk-distributor model. Such complementarity should eventually lead to more equitable and sustainable public transport systems in cities that are changing fast and where the development of paratransit operators has, in one way or another, contributed to the inclusion of the poorest sectors of society in the city.
\end{abstract}

\section{$1 \quad$ Introduction}

Paratransit services are by and large a standard feature of cities in the Global South ${ }^{1}$. With a few exceptions, road-based public transport systems represent the more utilized mode of motorized transport in the Urban South. In these systems, paratransit operations have often emerged as the more viable option (see Table 1).

Paratransit services have been resilient to public sector efforts to transform public transport, and they have also adapted their operations to ever more complex urban contexts (Avellaneda García 2007;

\footnotetext{
'The term "paratransit" conventionally describes a flexible mode of passenger public transportation that does not necessarily follow fixed routes or schedules, typically in the form of small- to medium-sized buses. In the Global South, paratransit services are usually provided for the general population, often by unregulated or illegal operators within the informal sector. For this reason, paratransit in the Global South is sometimes also referred to in the literature as "informal" transport. The term paratransit is preferred to informal transport in this paper as these services are not necessarily provided by informal businesses or unregulated. However, it should be noted that in instances where paratransit services are fully regulated and provided by businesses within the formal sector, they usually first emerged as unregulated and informal.

${ }^{2}$ In this document, the concept of flexibility refers to the operational flexibility of paratransit services. Operational flexibility is described as the paratransit sector's ability to operate without schedules (or headways) and, in some cases, its capacity to modify routes when conditions warrant.
}

a pablo.salazarferro@uct.ac.za

b roger.behrens@uct.ac.za

Copyright 2015 Pablo Salazar Ferro and Roger Behrens

http://dx.doi.org/10.5198/jtlu.2015.389

ISSN: 1938-7849 | Licensed under the Creative Commons Attribution - NonCommercial License 3.0.

The Journal of Transport and Land Use is the official journal of the World Society for Transport and Land Use (WSTLUR) and is published and sponsored by the University of Minnesota Center for Transportation Studies. 
Montezuma 1996). As cities have grown and developed, so has the paratransit network. Based largely on discrete and direct service route implementation, they connect different areas of cities, displaying demand responsiveness and flexibility ${ }^{2}$. Yet this flexibility has not always been accompanied by an evolution in their business practices and company structures (Montezuma 1996). Most paratransit business sectors in the Global South are highly fragmented, and thus are difficult to regulate by transport or local planning authorities. Absent or weak regulations are then reflected in paratransit operations; they contribute to congestion and pollution problems, and they display dangerous behaviors on the road.

Transformation (or eradication) of the paratransit sector is a complex challenge. In most cases, it is a political process and might require extended negotiation. In all cases, it is socially problematic; paratransit operations provide access to the city for (and are often provided by) the poorest sectors of society (Avellaneda García 2007). In addition, the paratransit industry is not limited to simply vehicle operations as it includes indirect service providers that base their livelihood on the existence of these transport services.

The emergence of bus rapid transit (BRT) systems in the Urban South presented authorities with a new opportunity to restructure entire public transport systems, including incumbent paratransit operations. The rapid and expanding interest in BRT systems represents an inflexion point in the development of public transport in cities of the Global South. This paper investigates the effects of the changing relationships between paratransit operations and recently implemented BRT systems in an urban setting. By focusing on the challenges of implementing feeder-trunk-distributor BRT models, it is argued that the inclusion of existing paratransit operations can lead to operational complementarity. Operational complementarity, as an element of integration, is vital when attempting to implement a sustainable public transport restructuring project.

The paper presents selected results of an ongoing research project that focuses on the interactions between "formal" and paratransit transport services. The research was based on the case-study method. Starting with a pool of cities in the midst of planning or implementing public transport restructuring programs, ${ }^{3}$ potential cases were categorized on the basis of a spectrum of approaches to paratransit recognition and integration, and "extreme" cases (i.e., cities at opposing ends of the spectrum of approaches) were selected for study. Case-study selection was "information-oriented" ${ }^{4}$. Consistent with the phronetic approach to research, as described by Flyvbjerg (2006), the objective was not to unearth universal laws or generalizations, but rather to identify consequences of transformational programs that need to be taken into account in current processes involving BRT networks.

Two main case studies are drawn on in this paper: Bogota (Colombia) and Santiago (Chile). Limited information from other cities gathered during the research process is, however, also presented. In the larger research project, other detailed cases were included: Cape Town (South Africa), Quito (Ecuador) and Accra (Ghana); however, the two above mentioned cases present consequences of particular relevance to the focus of this paper (i.e., investigating the territorial implications of changing relationships between paratransit and recently implemented BRT systems). The paper investigates the likely results of moving from direct services to feeder-trunk-distributor models by first describing the feeder-trunk-distributor model and then presenting cases (Santiago and Bogota) where such a dynamic was evidenced.

\footnotetext{
${ }^{3}$ The initial pool of cities consisted of eight African cities, Cape Town, Johannesburg and Port Elizabeth (South Africa), Accra (Ghana), Dakar (Senegal), Dar es Salaam (Tanzania), Lagos (Nigeria) and Nairobi (Kenya); four Asian cities, Ahmedabad and Delhi (India), Bangkok (Thailand) and Jakarta (Indonesia); and nine Latin American cities, Bogota (Colombia), Caracas (Venezuela), Curitiba, Rio de Janeiro and Sao Paulo (Brazil), Lima (Peru), Mexico City (Mexico), Quito (Ecuador) and Santiago (Chile).

${ }^{4}$ According to Flyvbjerg (2006), 'information-oriented' case selection, as a research strategy, aims at maximizing data or information from a small number of cases. The selection of cases is, therefore, carried out according to expectations about their content. This approach to case studies is similar to Ragin's (1999) case-oriented selection, which is directed at understanding few cases with substantive significance.
} 
Considering that there is no intention to generalize cause-consequence relationships, but rather to identify possible outcomes, the tentative conclusions of the paper are offered as beacons for policy discourse in contexts where trunk-and-feeder BRT systems are envisioned as the path to paratransit reform.

The document is divided into five main sections. First, a description of current public transport restructuring approaches is presented. Special attention is given to projects that introduce catalytic BRT systems meant to start the public transport overhaul and that compose the larger pool of possible cases described above. The second section then analyzes how the move from direct services to trunk-andfeeder services impacts paratransit services and, more broadly, the public transport system of cities in the Global South. The following section presents and describes territorial implications of the move toward trunk-and-feeder services; impacts are identified at two different scales. After broadly describing the territorial impact at each scale, the cases of Bogota and Santiago are used to further describe the urban implications of the process. The fourth section introduces a discussion on the possible role of paratransit services in current transformational processes that seek to move away from direct services. Finally, the fifth section concludes with more general observations and reflects on related impacts in other areas of the city.

Table 1: Paratransit dependency in selected cities' road-based public transport systems.

\begin{tabular}{|c|c|c|c|c|c|c|}
\hline \multirow{2}{*}{ City, Country } & \multirow{2}{*}{ Year } & \multicolumn{3}{|c|}{ Modal splits, selected motorized modes } & \multicolumn{2}{|c|}{ Public road-based modal splits } \\
\hline & & Private car & Public rail-based modes & Public road-based modes & 'Formal' & Paratransit \\
\hline \multicolumn{7}{|l|}{ Latin America } \\
\hline Caracas, Venezuela & 2007 & $27 \%$ & $20 \%$ & $53 \%$ & $26 \%$ & $74 \%$ \\
\hline Mexico City, Mexico & 2007 & $21 \%$ & $14 \%$ & $65 \%$ & $11 \%$ & $89 \%$ \\
\hline Quito, Ecuador & 2002 & $25 \%$ & -- & $75 \%$ & $10 \%$ & $90 \%$ \\
\hline \multicolumn{7}{|l|}{ Africa } \\
\hline Abidjan, Ivory Coast & 1998 & no data & -- & $100 \%$ & $37 \%$ & $63 \%$ \\
\hline Algiers, Algeria & 2004 & no data & $3 \%$ & $97 \%$ & $3 \%$ & $97 \%$ \\
\hline Cairo, Egypt & 1998 & no data & $39 \%$ & $61 \%$ & $15 \%$ & $85 \%$ \\
\hline Cape Town, South Africa & 2004 & $45 \%$ & $30 \%$ & $25 \%$ & $28 \%$ & $72 \%$ \\
\hline Casablanca, Morocco & 1998 & no data & - & $100 \%$ & $72 \%$ & $28 \%$ \\
\hline Dakar, Senegal & 2003 & no data & $2 \%$ & $98 \%$ & $5 \%$ & $95 \%$ \\
\hline Dar es Salaam, Tanzania & 2008 & $13 \%$ & - & $87 \%$ & $2 \%$ & $98 \%$ \\
\hline Nairobi, Kenya & 2008 & $33 \%$ & no data & $67 \%$ & $29 \%$ & $71 \%$ \\
\hline Tunis, Tunisia & 2000 & no data & $28 \%$ & $72 \%$ & $100 \%$ & $0 \%$ \\
\hline \multicolumn{7}{|l|}{ Asia } \\
\hline Jakarta, Indonesia & 1998 & no data & $2 \%$ & $98 \%$ & $66 \%$ & $34 \%$ \\
\hline Manila, Philippines & 1998 & no data & $3 \%$ & $97 \%$ & $22 \%$ & $78 \%$ \\
\hline Teheran, Iran & 1998 & no data & - & $100 \%$ & $44 \%$ & $56 \%$ \\
\hline
\end{tabular}

Sources: Author using Godard (2008), Flores and Zegras (2012), Grey (2006), Gschwender (2005), Lizarraga (2012), UATP and UITP (2010).

\section{Public transport restructuring approaches}

Recent public transport restructuring processes in cities of the Global South are, in many cases, radical attempts at the transformation of existing systems. Examples are notable South American cases (mainly Bogota, and to a lesser extent, Quito), where the introduction of a new mode or a new technology is regarded as an opportunity to substitute existing paratransit services (Gauthier and Weinstock 2010; Pardo 2009). Numerous cities in different locations of the Urban South have planned or implemented restructuring projects (see Table 2). Apart from the introduction of BRT, one of the main objectives 
is to absorb incumbent paratransit companies, expecting them to transform into "modern" operating companies.

Different tactics have been tried when engaging with existing paratransit operators. Some cities negotiate with vehicle owners (e.g., Quito's feeder services), while others, using the more common approach, deal with associations of owners (e.g., Bogota, Cape Town). In both approaches, not all incumbent operators can typically be included, and thus when their route is affected by the new project, a significant number are forced to leave the system or to move to other transport corridors (Salazar Ferro et al. 2012). This last option is not available to paratransit operators if the restructuring project comprises the entire city (e.g., Transantiago's road-based services in Santiago), as opposed to the more common phased transformation of selected transport corridors.

Irrespective of whether they are willingly involved or they are left with no other option, paratransit operators included in the restructuring process experience major changes. First, they need to adjust their daily practices to suit the new business model; they are compelled to move away from traditional practices (e.g., daily income, relatively informal labor relations, limited vehicle maintenance) to a more structured type of contract (e.g., gross cost contracting, labor and social responsibilities to employees, mandated capital investments in fleets). Second, in terms of operations, the implementation of BRT systems generally results in a change from direct services typical of paratransit operations to a feedertrunk-distributor model.

Table 2: Selected BRT implementation dates.

\begin{tabular}{|c|c|c|}
\hline City, Country & BRT system name & First implementation date \\
\hline \multicolumn{3}{|c|}{ Selected operational BRT (or similar) systems } \\
\hline Curitiba, Brazil & Rede Integrada de Transporte (RIT) & 1974 \\
\hline Quito, Ecuador & $\begin{array}{l}\text { Trolebus } \\
\text { Ecovia } \\
\text { Corredor Central-Norte }\end{array}$ & $\begin{array}{l}1995 \\
2001 \\
2004 \\
\end{array}$ \\
\hline Bogota, Colombia & Transmilenio & 2000 \\
\hline Sao Paulo, Brazil & Sistema Interligado & 2003 \\
\hline Jakarta, Indonesia & Transjakarta & 2004 \\
\hline Mexico City, Mexico & Metrobus (Insurgentes) & 2005 \\
\hline Pereira, Colombia & Megabus & 2006 \\
\hline Guayaquil, Ecuador & Metrovia & 2006 \\
\hline Santiago, Chile & Transantiago (road-based bus network) & 2007 \\
\hline Lagos, Nigeria & BRT-Lite & 2008 \\
\hline Delhi, India & (Delhi Bus Corridor) & 2008 \\
\hline Johannesburg, South Africa & Rea Vaya & 2010 \\
\hline Lima, Peru & Metropolitano & 2010 \\
\hline Cape Town, South Africa & MyCiTi & 2011 \\
\hline \multicolumn{3}{|c|}{ Selected systems in planning phases } \\
\hline Dar es Salaam, Tanzania & DART & exp. 2013 \\
\hline Pretoria, South Africa & (Tshwane BRT) & exp. 2013 \\
\hline Rustenburg, South Africa & Rustenburg Rapid Transport (RRT) & exp. 2013 \\
\hline
\end{tabular}

Source: Authors using http://brtdata.org (visited August 2012), Gauthier and Weinstock (2010), Hidalgo and Pai (2010), Pardo (2009). 


\section{$3 \quad$ Moving from direct services to feeder-trunk-distributor services}

The move to a feeder-trunk-distributor model necessitates major change in the nature of the paratransit sector. Direct services express in the urban territory the logics of route creation by a private, artisanal and fragmented sector. The creation of paratransit routes is deeply rooted in, and linked to, disorganized urban growth typical of the Global South: a spatial growth largely based on the expansion of poor residential areas on the periphery (Obeng-Odoom 2009; Kumar and Barrett 2008; Avellaneda García 2007; Montezuma 1996). In Latin American cities, for instance, the paratransit network was built through the historical accretion of single independent routes implemented once a new peripheral area sought public transport services (Figueroa and Reyes 1996). Some of the consequences of this have been the confluence of routes into the city centers and problematic levels of congestion on the primary radial corridors on which paratransit service routes merge and overlap (Figueroa and Reyes 1996).

The layout of direct route-based paratransit services epitomizes and exacerbates the monocentric urban forms common in the Global South. In Africa and South America, more than one-third of formal jobs are located in the historical central area (Cervero 2013). The employment-related importance of the city center logically results in attraction of inhabitants; or, in other words, it produces the main destination for commuter trips throughout the city. For middle- and lower-income inhabitants located in peripheral areas and dependent on public transport, cheap paratransit services represent the more affordable solution to access employment opportunities (Godard 2013; Figueroa 2005). As lower-income areas of cities expand, they are first served by (new) paratransit services that link the peripheries with the urban core.

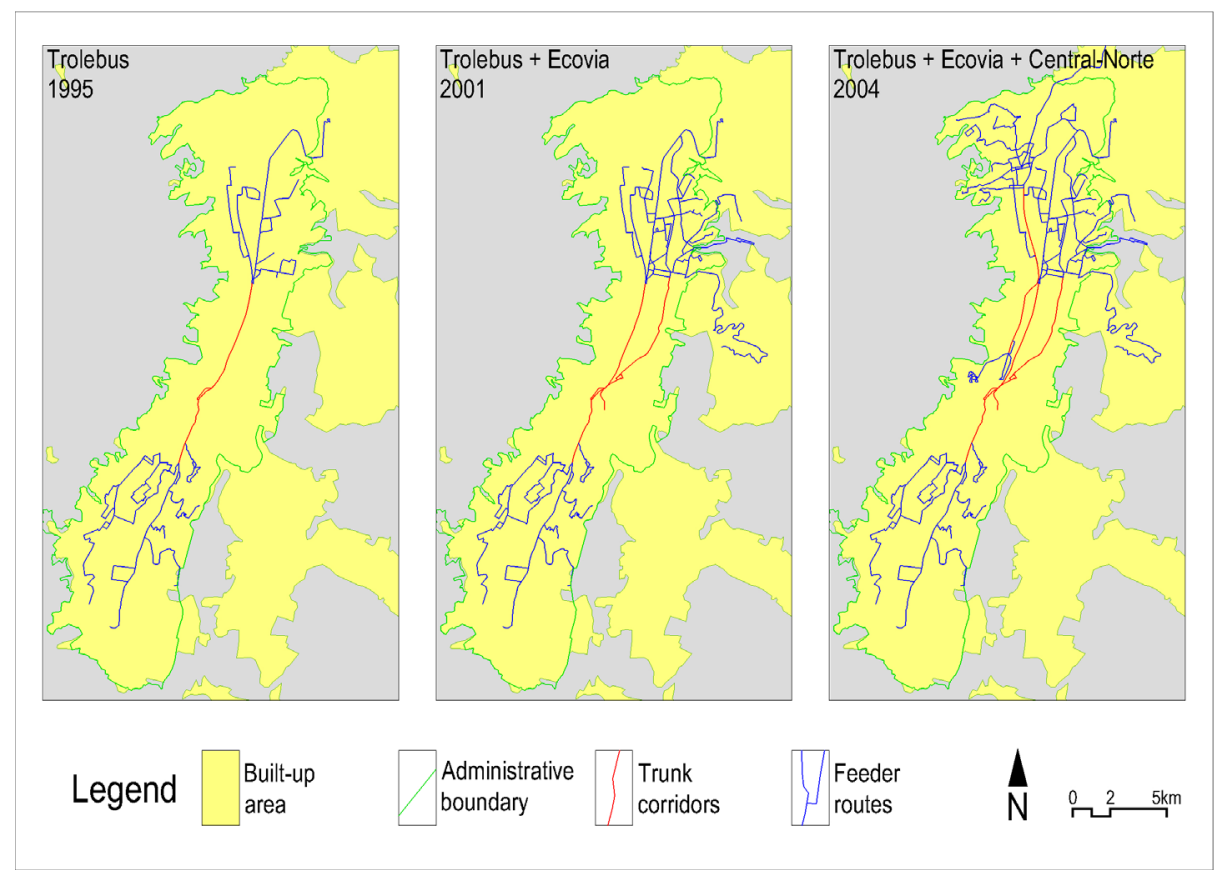

Figure 1: Quito's BRT network evolution, Trolebus (1995), Ecovia (2001) and central-Norte corridor (2004) Source: Authors using Municipio del Distrito Metropolitano de Quito (2009).

Congestion (the archetypical product of an "inefficient" system) and pollution are regarded by some authors as the fundamental transport problems that the implementation of BRT attempts to reduce (Gauthier and Weinstock 2010; Gbadamosi 2010). The trunk-and-feeder BRT option seeks to

${ }^{5}$ Godard (2008) defines artisanal transport operations as those performed by individuals using private vehicles that follow a framework defined by a collective set of rules that can be more or less demanding. 
"formalize" existing services, reduce externalities and optimize operational costs. With regard to the latter, some authors argue it would be too costly for authorities to provide quality direct services between all origins and destinations in a city (Rivasplata 2008). Trunk-and-feeder services require different operating practices than those the recently included operators are familiar with.

The conceptual operational model behind most BRT systems of the Urban South is generally to develop high-capacity (usually infrastructure-heavy) trunk corridors on main roads where public transport demand is highest (Figueroa 2005). On these corridors, albeit dependent on the station spacing and the types of routes, speeds and capacities are theoretically higher than before. In theory, "in-the-market" competition is removed as paratransit operations are moved away from the corridor. To complement these trunk services, feeder operations are introduced. Feeder vehicles operate in corridors with lesser passenger demands and require less, if any, infrastructural investments. The model can then be reproduced in other corridors, with larger territorial coverage being the ultimate objective (Figure 1 shows this process in Quito between 1995 and 2004). Feeder-trunk-distributor services are significantly more rigid ${ }^{6}$ than the direct services they replace. This rigidity is more apparent in the trunk sections of the network.

\section{$4 \quad$ Territorial implications}

The outcomes, positive or negative, of the move from paratransit direct services to formal feeder-trunkdistributor models are not generalizable; city contexts play an important role in determining outcomes, and paratransit path dependencies influence the extent of change possible. Nonetheless, the detailed analysis of selected cases helps typify certain implications of, and the obstacles facing, trunk-and-feeder model implementation processes.

\subsection{Impacts on peripheral areas}

Due to their demand responsiveness, flexible nature and their mostly disorganized decisions, paratransit operators have established public transport systems that cover most of the urban territories in which they operate. Such coverage is explained by the need of inhabitants to travel, and by the opportunities available to paratransit operators (Avellaneda García 2007). Conceptually, paratransit direct routes group in central areas, where the levels of activity are most intense and where passenger demand is highest, and they gradually disperse through secondary and minor roads as they move away from the central areas. As a result, while in central areas, routes tend to overlap. These same routes will have limited competition in the more peripheral areas of the city.

In Santiago (Chile), before the implementation of Transantiago's BRT elements, the paratransit system covered most of the urban territory. Citywide urban accessibility, albeit with considerable quality of service shortcomings, was provided. In 2001, approximately 98 percent of inhabitants were less than 800 meters $^{7}$ away from any one of the 323 paratransit direct routes (Forray and Figueroa 2011). Bus frequencies averaged four minutes between services, and most trips did not require transfers (only 7 percent to 15 percent of peak-hour trips required a transfer) (Forray and Figueroa 2011).

After Transantiago's implementation in 2007, most of these characteristics were lost with the introduction of a rigid feeder-trunk-distributor model. As a result of the move from direct services to feeder and trunk services, the need to transfer increased dramatically. It is currently estimated that approximately 60 percent of trips require one or more transfers (Gómez Lobo, 2012).

${ }^{6}$ In this paper, the term "rigidity" is used to refer to inflexibility in public transport systems. As its antonym, flexibility is understood as the transport mode's ability to change, primarily, its routes (including creation, modification and substitution) and its schedules or frequencies.

${ }^{7}$ Forray and Figueroa (2011) state that inhabitants are eight urban blocks away from any one route. One urban block is approximately 100 meters long. 
The optimization of routes appears not to have met its original objectives with respect to route reduction. In 2005, the envisioned total number of bus routes was 193. In May 2007 when the system launched, this number had increased to 266, which was still lower than the previous total number of paratransit routes (Briones 2009). However, between May and December 2007, Transantiago authorities had to significantly increase the number of feeder (and trunk) routes to a level comparable to the previous direct routes-based network (Figure 2). Currently, it is unclear if the higher number of total routes has resulted in greater territorial coverage when compared with the situation before 2007; nonetheless, some sources question if coverage is sufficient in peripheral (feeder) areas (Briones 2009; Morandé Lavín and Doña 2007). Briones (2009) argues that the system changes resulted in both a lessthan-adequate trunk network, and a less-than-convenient feeder network that was not dense enough in peripheral areas.

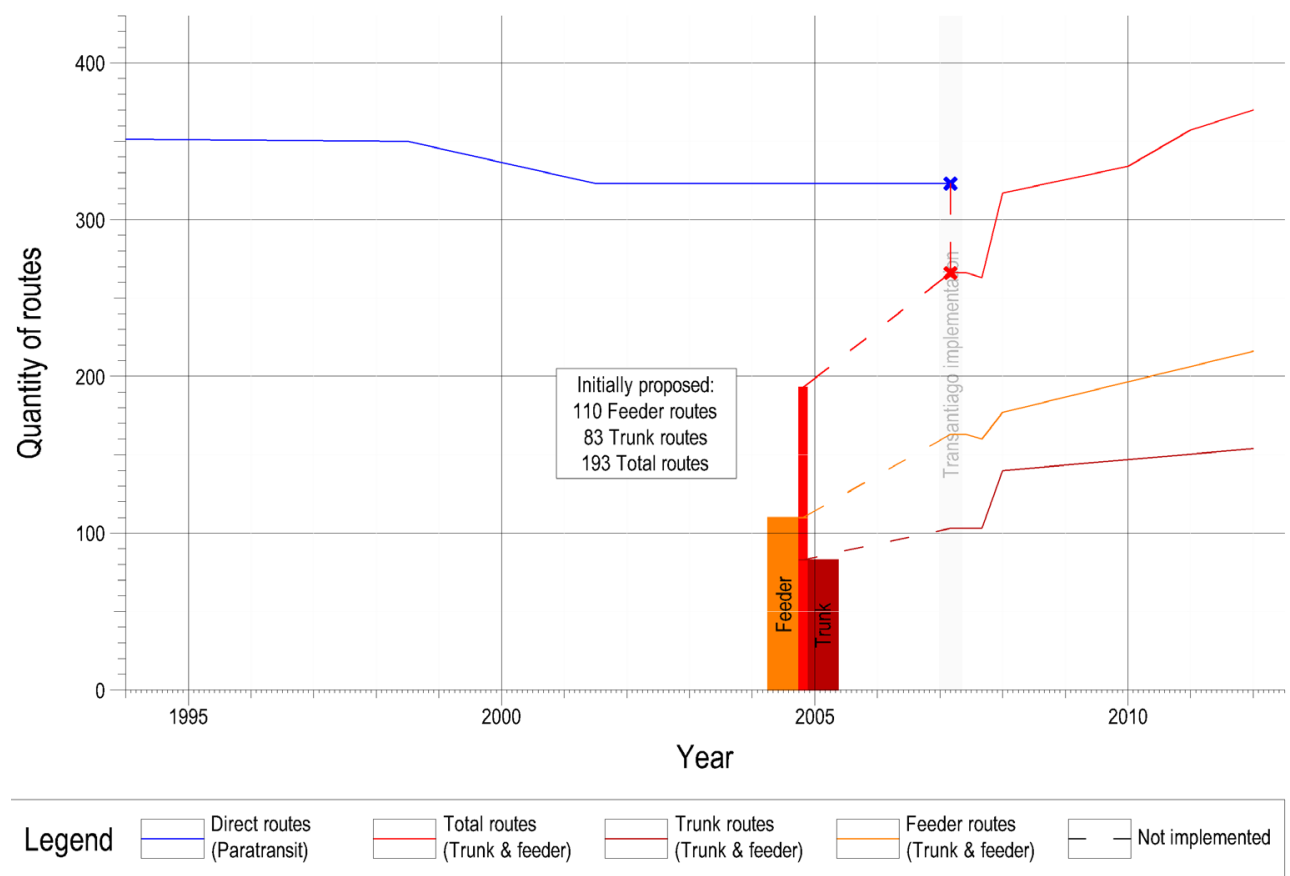

Figure 2: Evolution on Santiago's road-based public transport routes.

Sources: Author using Briones (2009), Dourthe et al. (1998), Muñoz (2012).

Reduced numbers of routes in some areas produced some unforeseen results. Inhabitants of the city peripheries, out of necessity, had to adjust their travel patterns to suit this new public transport system. Analysis undertaken two years after Transantiago's introduction explains how inhabitants of one the city's poorest areas had to adapt to the changes introduced (Jouffe and Lazo Corvalán 2010). People chose to acquire a private vehicle, to reduce the area of the city in which they look for a job, and to change jobs or adjust their work schedule (e.g., work at night or work double shifts) to better fit the new system's supply (Jouffe and Lazo Corvalán 2010). In most cases, these changes in travel patterns portray a reduction in accessibility derived from the public transport system.

Loss or reduction of accessibility is exacerbated by unplanned peripheral city growth. Like most cities in the Global South, Santiago has population growth that occurs primarily in peripheral lowincome neighborhoods (Briones 2009; Figueroa and Orellana 2008; Figueroa and Reyes 1996). Some of these newly built areas are the zones most affected by the substitution of paratransit services with a BRT system and by the move from a flexible to a rigid transport model. If the current rigid feeder- 
trunk-distributor model remains unchanged, newly developed areas of the city will likely continue to be relatively isolated from the "formal" public transport system. Based on current growth trends and inhabitants' travel patterns, in these peripheral areas, a more flexible and demand responsive system is likely to be the more efficient solution to mobility and accessibility needs.

\subsection{Citywide repercussions}

BRT has been described as a semi-rigid system; it is more flexible than a metro-type rail system but more rigid than conventional buses (Vuchic 2007). It is certainly an infrastructure-heavy system when compared to the typical paratransit system. Irrespective of whether the BRT implementation plan is gradual (i.e., corridor-phased incremental execution of a long-term plan) or a once-off large scale change, implementation of infrastructure-heavy trunk corridors is usually based on the identification of one or more existing roads where passenger demand is highest. More often than not, the first phases of BRT introduction focus on historically established public transport corridors.

The relationship between BRT trunk corridors and urban form is sometimes not adequately taken into account, yet this link remains a key feature when planning public transport systems. When analyzing different urban forms and the need for high-capacity lines (in the form of metro-type networks), Gilbert (2008) explains that linear-shaped cities require less infrastructure-heavy public transport lines ${ }^{8}$ for wide territorial coverage than cities with more spread urban forms. ${ }^{9}$ The same length of BRT trunk service will cover more of the urban area of linear-shaped cities than that of cities with more spread urban forms (see Figure 3). This conclusion is transferable to other modes. While being relatively cheaper and easier to implement than rail-based modes (Lupano and Sánchez 2009), BRT trunk corridors still require considerably more capital investments than the paratransit-based network they are meant to replace.

In Bogota (Colombia), even though BRT implementation significantly and positively changed the public transport system, its coverage is still relatively limited compared to that of the paratransit network. This is reflected in the modal share within the public transport system. In 2010, Transmilenio (Bogota's renowned BRT system) was responsible for approximately 20 percent of all public transport trips, and the paratransit sector was responsible for the remaining 80 percent (Alcaldía Mayor de Bogotá 2011). What is more, after the initial phases of Transmilenio, paratransit vehicles were not necessarily replaced; they were pushed to other roads and secondary public transport corridors.

The lack of complementarity and relative isolation between Transmilenio and the existing paratransit services is manifest in the evolution of the public transport fleet. The first phases of BRT implementation required operating companies to scrap a specified number of vehicles (2.7) for every new bus introduced in the system. The process did not yield the expected outcomes, and the overall number of vehicles in the paratransit system remained the same (see Figure 4). Different authors present a similar scenario: a large oversupply of vehicles. Ardila Gómez (2007 and 2005) argues that even though approximately 3500 buses were scrapped, paratransit companies not included in the process simply kept introducing more buses into the system. Oversupply of vehicles was estimated at 7500 buses. Gilbert (2008) suggests that in 2006, if the scrapping process had been successful, there should have been approximately 10,000 vehicles, but he estimates that more than 20,500 vehicles were still operating in the city. These numbers confirm that, in corridors outside of Transmilenio, congestion and pollution intensified (Echeverry et al. 2005).

Like most implementation processes, Bogota's initial plan was based on gradually adding trunk corridors to the BRT network. If an even rudimentary complementarity between "formal" and paratransit services is not achieved, the implementation of the complete Transmilenio plan is likely to face sig-

${ }^{8}$ Fewer lines, not necessarily shorter lines.

${ }^{9}$ Spread urban forms refer exclusively to the shape of the city and not to the density. 
nificant obstacles when engaging with the remaining paratransit operators. Pushing paratransit operators to other corridors renders the ensuing roll out of phases incrementally more complex. For trunk-and-feeder networks, coverage of the urban territory will only be partial. The likely outcome is that several areas of the city will be out of reach of the trunk-and-feeder network (Salazar Ferro et al. 2012; Lleras 2005), and for a period of time, the city will continue to rely, in part, on paratransit services (Salazar Ferro et al. 2012). The lack of dialogue between the new "formal" modes and the incumbent paratransit services forces the latter to cluster their operations in corridors where BRT has not been built, potentially worsening overall urban mobility and general accessibility in some areas.

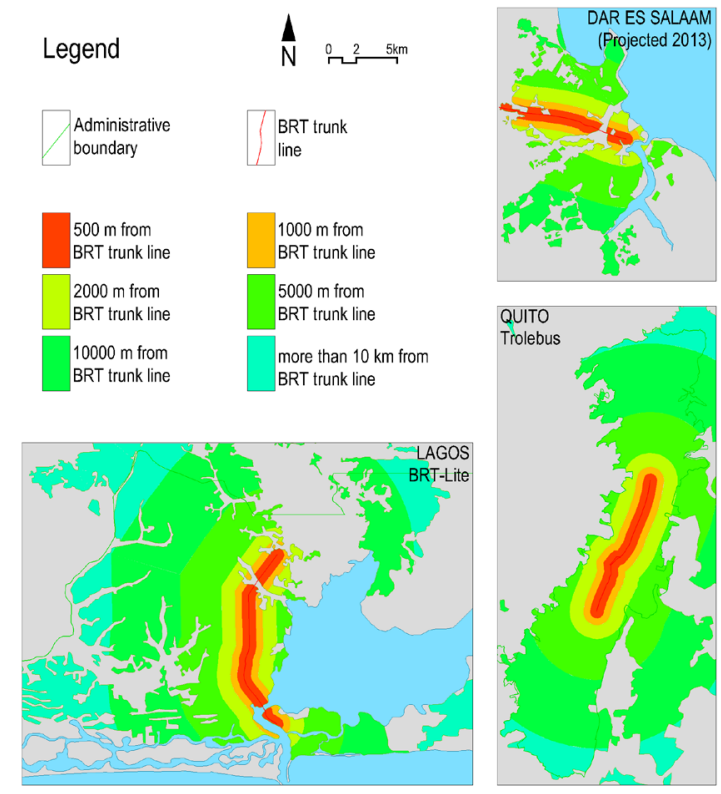

Figure 3: Location of trunk BRT corridors in Lagos (Nigeria), Dar es Salaam (Tanzania) and Quito (Ecuador). Sources: Authors using Municipio del Distrito Metropolitano de Quito (2009), Gandy (2006), Diaz Olvera et al. (2003).

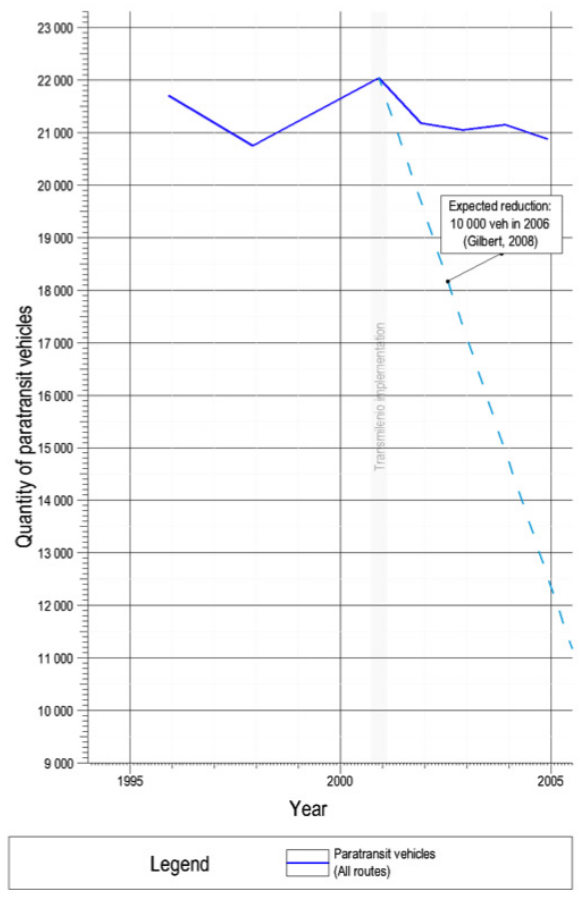

Figure 4: Evolution of Bogota’s number of public transport vehicles (excluding Transmilenio buses). 


\section{$5 \quad$ A place for paratransit services?}

Current attempts at public transport reform often rely on a drastic move away from the direct services model generated over time by the paratransit sector. In this process, some of the more valuable characteristics of the paratransit-dependent transport systems of the Urban South are lost or overlooked. It is argued that certain problematic aspects of the transition to feeder-trunk-distributor models could be mitigated by the acknowledgement and possible use of some advantages of the paratransit sector.

Two scales of effects have been identified when moving to trunk-and-feeder models. Two potential relationships between paratransit and newly implemented systems can be proposed in relation to these scales. First, at the local scale, paratransit services can conceivably be of use in peripheral areas of the city (where most urban growth happens) because of their flexibility and demand responsiveness. Second, at the citywide scale, a complementary relationship between the newly implemented mode(s) and the existing paratransit sector can increase the coverage of the public transport system. Most current public transport restructuring initiatives discount these possibilities (Salazar Ferro et al. 2012). Reasons and justifications can be found in the complexity of engaging with a paratransit sector with widely different business and operational logics to those of "modern" public transport modes.

Paratransit inclusion in ongoing public transport reform initiatives is possible, but various obstacles have been identified. First, negotiations for paratransit inclusion in the new system can be long and taxing. After studying some of South Africa's current BRT implementation initiatives, Schalekamp and Behrens (2010) explain that the difficult process of engaging with incumbent operators has resulted in unforeseen blockages and delays throughout the implementation process. It is argued that any engagement process will have to take into account context-specific paratransit-related path dependencies, and that transferring engagement approaches without contextual adaptation is unlikely to be successful (Schalekamp and Behrens 2010).

A second key obstacle to paratransit inclusion as "formal" operators in current BRT processes is the cost to the system resulting from this inclusion. Flores and Zegras (2012) studied the costs of different phases of BRT implementation (mainly trunk services) in Mexico City. They propose a conceptual continuum of options when engaging with existing paratransit operators. The range of options is limited by, on the one end, "fostering" changes and, on the other end, "forcing" changes. Pertaining to fostering change, they argue costs take the form of increasingly complex negotiations with incumbent operators and associated compromises in operations design. With regard to forcing changes, they argue costs are social and political in nature. Their main conclusion is that there are significant but different costs associated with fostering or forcing paratransit operators into the new BRT network, and that a fostering approach may be more expensive in the long term (Flores and Zegras 2012).

If the move away from direct services is envisioned and warranted, the lingering question of what can be the role of paratransit, if any, in BRT feeder-trunk-distributor models remains. The answer will depend on the city's context and on the objectives of the restructuring program taking place. It is important, in any case, to note that decisions in terms of the degree of inclusion of paratransit operators (limited or wholesale) will result in different risks (including costs, territorial coverage and accessibility issues) during the transformational process.

\section{Conclusions}

This paper undertook to investigate- through case studies and from a spatial perspective- the likely consequences of moving from direct services to trunk-and-feeder services. While not intending to generalize to all cities in the Global South, the analysis of the two case studies presented in this paper helps identify likely difficulties in implementing this change. In the case of Santiago, while the public trans- 
port system restructuring was uniquely comprehensive from a spatial perspective, route numbers have not declined as planned and authorities ended up making amendments to the network, particularly in peripheral locations, that replicated some of the features of the paratransit services that were replaced (i.e., more coverage and less rigid feeder service concession area boundaries). In the case of Bogota, paratransit services have persisted, and the citywide vehicle fleet has not declined as planned. It is argued, therefore, that a case can be made for a more significant inclusion of incumbent paratransit services in public transport reform. An acknowledgement of the benefits inherent to paratransit operations (mainly their flexibility and territorial coverage), can point to an eventual role for them in a multimodal and integrated system.

Successful complementarity between formal and paratransit modes is possible. One type has been observed in Southeast Asian cities by Cervero (1991). As a result of the poor state of roads (i.e., narrow roads, faulty pavement and/or lack of road hierarchy), the author argues that paratransit services in the form of small vehicles have flourished (Cervero 1991). They operate specialized local area services that complement the existing high-capacity modes with relative success and acceptability from inhabitants. Similar to this analysis, Godard (2001) has stated that paratransit services are more adapted and more adaptable to those lower-income peripheral areas. This characteristic partly explains their growing importance.

Public transport system overhauls are certainly justified and needed in the Urban South, but current radical approaches to restructuring systems encounter significant obstacles, and it is questionable whether the proposed transformation will be fully achieved in many cities. The BRT feeder-trunkdistributor model, if properly evaluated, is an appropriate solution in certain contexts, but it should not be considered the only solution. Other alternatives are available, each with benefits and disadvantages.

Existing direct service networks express a multitude of individual links that are operated independently. Established paratransit operators have built a dense network that fits the wishes of inhabitants to travel without transfers between various points in the city. This type of network is similar to what Dupuy (1992) describes as a network built out of "desire lines," as opposed to a "simplified network" (see Figure 5). The latter is based on an optimization of the former from an operating perspective. BRT trunk-andfeeder systems fit this description. The transition from direct services to feeder-trunk-distributor services can be problematic from a passenger perspective. This does not suggest that it is always an unwarranted move, but rather that the overhaul requires an analysis that is sometimes omitted.
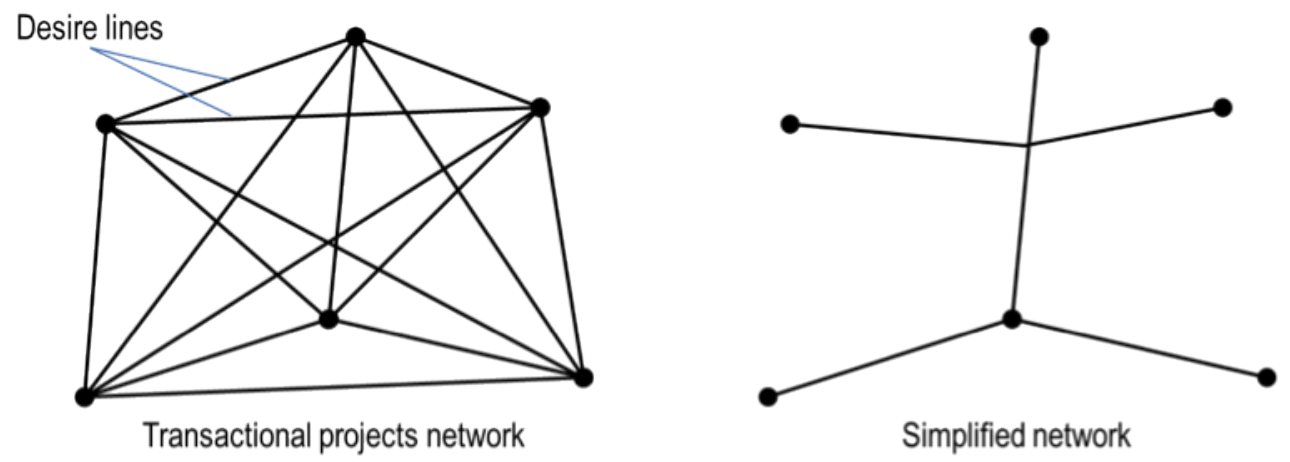

Figure 5: Conceptual model of direct service network and feeder-trunk-distributor network.

Source: Dupuy (1992). 
Most cities in the Global South have stable and established transport corridors where the implementation of trunk services is warranted to reduce overall congestion. Provision of feeder services allows for wider system coverage. But trunk-and-feeder implementation has major effects on the territory and on travel patterns that should not be ignored. The two key points identified in this paper are: a loss of accessibility in peripheral areas; and the need for integration with other existing modes to achieve citywide coverage when gradual implementation is envisioned. These conclusions resonate with Godard's (2013) analysis of West and North African transport systems, in which he argues that the implementation of formal paratransit multimodal networks will be needed to provide public transport services in cities with rapid (and, more particularly, sprawling) urban growth.

Feeder-trunk-distributor service models, as one example of on-going restructuring processes, have other impacts on urban form and structure. These effects are not exclusive to trunk-and-feeder systems, but they require analyses that are sometimes overlooked during planning or implementation phases. In analyzing Bogota's recent changes, Salazar (2008) argues that one of the problems public transport initiatives need to overcome is the lack of articulation with the existing urban structure. The author explains that Transmilenio's flat fare and express-services model have increased the importance of the historical center of the city, and undermined the planning framework that envisioned the development of secondary activity nodes. Such analysis resonates with Bresciani's (2002) understanding of the challenges that the recent plan for Santiago's transport system faced. According to Bresciani (2002), the new transport system should respond to the ongoing changes in the city, mainly changes concerning the location and the importance of nodes. Cities in the Global South are evolving from monocentric to polycentric structures and restructuring initiatives need to recognize these changes. A complementary relationship between the newly implemented modes and the existing paratransit services can lead to restructuring projects and systems that exhibit better interactions with dynamic urban structures.

\section{Acknowledgement}

The research presented in this paper was funded by the Volvo Research and Educational Foundations, and forms part of a broader research program conducted by the African Center of Excellence for Studies in Public and Non-motorized Transport (ACET, www.acet.uct.ac.za).

The authors would also like to thank Gordon Pirie (deputy director of the African Center for Cities, University of Cape Town) for his valuable comments on an earlier version of this paper as well as the anonymous reviewers who suggested improvements to the first submitted draft.

\section{References}

Alcaldía Mayor de Bogotá. 2011. Documento técnico de soporte-modificación al plan de ordenamiento territorial de Bogotá. Secretaría de Planeación. Bogota, Colombia.

Global BRT Data. http//brtdata.org. Accessed August 2012.

Municipio del Distrito Metropolitano de Quito. 2009. Plan maestro de movilidad para el distrito metropolitano de Quito 2009-2025. Empresa Municipal de Movilidad y Obras Públicas. Quito, Ecuador.

UATP (African Association of Public Transport) and UITP (International Association of Public Transport). 2010. Public transport in Sub-Saharan Africa: Major trends and case studies. TransAfrica Consortium, Brussels, Belgium.

Ardila Gómez, A. 2007. How public transport's past is haunting its future in Bogota, Colombia. Transport Research Record 2038: 9-15.

Ardila Gómez, A. 2005. La olla a presión del transporte público en Bogotá. Revista de Ingeniería 21: $56-67$. 
Avellaneda García, P. 2007. Movilidad, pobreza y exclusión social-Un estudio de caso en la ciudad de Lima. Ph.D. dissertation, Universitat Autònoma de Barcelona, Barcelona, Spain.

Bresciani, L. E. 2002. Concentraciones dispersas-Plan de transporte urbano de Santiago y geografías de consumo. ARQ Ensayos y Documentos 52: 38-40.

Briones, I. 2009. Transantiago: Un problema de información. Estudios Públicos 116: 37-91.

Cervero, R. 2013. Linking urban transport and land use in developing countries. Journal of Transport and Land Use 6(1): 7-24.

Cervero, R. 1991. Paratransit in Southeast Asia: A market response to poor roads? Review of Urban and Regional Development Studies 3: 3-27.

Diaz Olvera, L., D. Plat, and P. Pochet. 2003. Transportation conditions and access to services in a context of urban sprawl and deregulation—The case of Dar es Salaam. Transport Policy 10: 287-298.

Dourthe, A., M. Wityk, H. Malbrán, and O. Figueroa. 1998. Déréglementation et re-réglementation du transport public urbain: Le cas de Santiago du Chili. CODATU VIII Conference, September 21-25. Cape Town, South Africa.

Dupuy, G. 1992. L'Urbanisme des Réseaux-Théories et méthodes. Armand Colin Éditeur, Paris, France.

Echeverry, J. C., A. M. Ibáñez, and A. Moya. 2005. Una evaluación económica del sistema Transmilenio. Revista de Ingeniería 21: 68-77.

Figueroa, O. 2005. Transporte urbano y globalización-Políticas y efectos en América Latina. Revista EURE (Santiago) 31(94): 41-53.

Figueroa, O., and A. Orellana. 2008. Transantiago: Gobernabilidad e institucionalidad. Revista EURE (Santiago) 33(100): 165-171.

Figueroa, O. and S. Reyes. 1996. Transporte y calidad de vida en las ciudades latinoamericanas: Sus relaciones con el uso del suelo y la contaminación urbana. Revista EURE (Santiago) 22(67): 29-44.

Flores, O., and C. Zegras. 2012. The cost of inclusion: Incorporating existing bus and paratransit operators into Mexico City's BRT. 12th Conference on Advanced Systems for Public Transport (CASPT), July 23-27. Santiago, Chile.

Flyvbjerg, B. 2006. Five misunderstandings about case-study research. Qualitative Inquiry 12(2): 219245.

Forray, R., and O. Figueroa. 2011. Transantiago: La malograda promesa de modernización del transporte publico. http://www.ciudadenmovimiento.org/index.php. Accessed July 2012.

Gandy, M. 2006. Planning, anti-planning and the infrastructure crisis facing Metropolitan Lagos. Urban Studies 43(2): 371-396.

Gauthier, A., and A. Weinstock. 2010. Africa: Transforming paratransit into BRT. Built Environment 36(3): 317-327.

Gbadamosi, K. 2010. An evaluation of the impact of bus rapid transit in urban intra-city passenger movement in Lagos State. 12th WCTR Conference, July 11-15. Lisbon, Portugal.

Gilbert A. 2008. Bus rapid transit: Is Transmilenio a miracle cure? Transport Reviews 28(4): 439-467.

Godard, X. 2013. Comparisons of urban transport sustainability: Lessons from West and North Africa. Research in Transportation Economics 40: 96-103.

Godard, X. 2008. Transport artisanal-Esquisse de bilan pour la mobilité durable. Inrets, Lyon, France.

Godard, X. 2001. Poverty and urban transport-Learning from African cities. South African Transport Conference (SATC). July 16-20. Pretoria, South Africa.

Gómez Lobo, A. 2012. The ups and downs of a public transport reform: The case of Transantiago. Serie documentos de trabajo SDT354, Universidad de Chile, Departamento de Economía, Santiago, Chile. 
Grey, P. 2006. Regulating the informal: Exploring the possibilities for formalizing the South African minibus-taxi industry. Master's dissertation, University of Cape Town, Cape Town, South Africa.

Gschwender, A. 2005. Improving the urban public transport in developing countries: The design of a new integrated system in Santiago, Chile. 9th Conference on Competition and Ownership in Land Transport, September 7-11. Lisbon, Portugal.

Hidalgo, D., and M. Pai. 2010. Evaluation of the Delhi Bus Corridor: Lessons learned and recommendations for improvement. 12th WCTR Conference, July 11-15. Lisbon, Portugal.

Jouffe, Y., and A. Lazo Corvalán. 2010. Las prácticas cotidianas frente a los dispositivos de movilidad. Revista EURE (Santiago) 36(108): 29-47.

Kumar, A., and F. Barrett. 2008. Stuck in traffic: Urban transport in Africa. Final report. World Bank, http://infrastructureafrica.org.

Lizarraga, C. 2012. Expansión metropolitana y movilidad: El caso de Caracas. Revista EURE (Santiago) 38(113): 99-125.

Lleras, E. G. C. 2005. Transmilenio y el transporte colectivo tradicional, una relación incierta. Revista de Ingeniería 21:84-93.

Lupano, J. A., and R. J. Sánchez. 2009. Politicas de movilidad urbana e infraestructura de transporte. CEPAL, United Nations, Santiago, Chile.

Montezuma, R. 1996. Le rôle du système de transport en commun dans le processus d'urbanisation désordonnée en Amérique Latine: Le cas de Bogota (Colombie). CODATU VII Conference, February $12-16$. Delhi, India.

Morandé Lavín, F., and J. E. Doña. 2007. Transantiago: El remedio que está matando al paciente. Trabajos de Investigación en Politicas Públicas 5: 3-17.

Muñoz, J. C. 2012. Transantiago, five years after its launch. Forthcoming World Bank Report.

Obeng-Odoom, F. 2009. The future of our cities. Cities 26: 49-53.

Pardo, C. F. 2009. Los cambios en los sistemas integrados de transporte masivo en las principales ciudades de América Latina. CEPAL, United Nations, Santiago, Chile.

Ragin, C. 1999. The distinctiveness of case-oriented research. HSR: Health Sciences Research Part II 34(5): $1137-1151$.

Rivasplata, C. 2008. Public transport integration in a privatized market-Recent policy lessons from abroad. CODATU XIII Conference, November 12-14. Ho Chi Minh, Vietnam.

Salazar Ferro, P., R. Behrens, and P. Wilkinson. 2012. Hybrid urban transport systems in developing countries: Portents and prospects. Research in Transportation Economics 39(1): 121-132. doi. org/10.1016/j.retrec.2012.06.004.

Salazar, J. 2008. Bogota 1992-2005: The reversal of the crisis and planning scheme. Mega-cities Comparative Study Conference, March 7-8. Tokyo, Japan.

Schalekamp, H., and R. Behrens. 2010. Engaging paratransit on public transport reform initiatives in South Africa: A critique of policy and an investigation of appropriate engagement approaches. Research in Transportation Economics 29: 371-378.

Vuchic, V. 2007. Urban Transit Systems and Technology. John Wiley and Sons: New York, USA. 